\title{
Article \\ Augmentation Index Is Inversely Associated with Skeletal Muscle Mass, Muscle Strength, and Anaerobic Power in Young Male Adults: A Preliminary Study
}

\author{
Dongmin Lee $^{1}\left(\mathbb{D}\right.$, Kyengho Byun ${ }^{2,3,4}$, Moon-Hyon Hwang ${ }^{3,4,5}$ and Sewon Lee $2,3,4, *(\mathbb{D})$ \\ 1 Department of Human Movement Science, Graduate School, Incheon National University, \\ Incheon 22012, Korea; dmdm1026@gmail.com \\ 2 Division of Sport Science, College of Arts \& Physical Education, Incheon National University, \\ Incheon 22012, Korea; kbyun21@inu.ac.kr \\ 3 Sport Science Institute, College of Arts \& Physical Education, Incheon National University, \\ Incheon 22012, Korea; mhwang@inu.ac.kr \\ 4 Health Promotion Center, College of Arts \& Physical Education, Incheon National University, \\ Incheon 22012, Korea \\ 5 Division of Health \& Kinesiology, College of Arts \& Physical Education, Incheon National University, \\ Incheon 22012, Korea \\ * Correspondence: leesew@inu.ac.kr; Tel.: +82-32-835-8572; Fax: +82-32-835-0788
}

Citation: Lee, D.; Byun, K.; Hwang, M.-H.; Lee, S. Augmentation Index Is Inversely Associated with Skeletal Muscle Mass, Muscle Strength, and Anaerobic Power in Young Male Adults: A Preliminary Study. Appl. Sci. 2021, 11, 3146. https://doi.org/ 10.3390/app11073146

Academic Editor: Daniela Galli

Received: 5 March 2021

Accepted: 28 March 2021

Published: 1 April 2021

Publisher's Note: MDPI stays neutral with regard to jurisdictional claims in published maps and institutional affiliations.

Copyright: (c) 2021 by the authors. Licensee MDPI, Basel, Switzerland. This article is an open access article distributed under the terms and conditions of the Creative Commons Attribution (CC BY) license (https:// creativecommons.org/licenses/by/ $4.0 /)$.

\begin{abstract}
Arterial stiffness is associated with an increased risk of cardiovascular disease. Previous studies have shown that there is a negative correlation between arterial stiffness and variables such as skeletal muscle mass, muscular strength, and anaerobic power in older individuals. However, little research has been undertaken on relationships in healthy young adults. This study presents a preliminary research that investigates the association between arterial stiffness and muscular factors in healthy male college students. Twenty-three healthy young males ( $23.9 \pm 0.5$ years) participated in the study. The participants visited the laboratory, and variables including body composition, blood pressure, arterial stiffness, blood parameters, grip strength, and anaerobic power were measured. Measurements of augmentation index (AIx) and brachial-ankle pulse wave velocity (baPWV) were performed to determine arterial stiffness. There were significant positive correlations among skeletal muscle mass, muscle strength, and anaerobic power in healthy young adult males. AIx was negatively associated with a skeletal muscle mass $(\mathrm{r}=-0.785, p<0.01)$, muscular strength $(\mathrm{r}=-0.500, p<0.05)$, and anaerobic power $(\mathrm{r}=-0.469, p<0.05)$, respectively. Likewise, AIx@75 corrected with a heart rate of 75 was negatively associated with skeletal muscle mass $(\mathrm{r}=-0.738, p<0.01)$, muscular strength $(\mathrm{r}=-0.461, p<0.05)$, and anaerobic power $(\mathrm{r}=-0.420, p<0.05)$ respectively. However, the baPWV showed no correlation with all muscular factors. Our findings suggest that maintaining high levels of skeletal muscle mass, muscular strength, and anaerobic power from relatively young age may lower AIx.
\end{abstract}

Keywords: skeletal muscle mass; muscular strength; anaerobic power; arterial stiffness

\section{Introduction}

Arterial stiffness, one of the factors indicating the function of blood vessels, is a main independent risk factor that can predict cardiovascular diseases [1]. Especially, this indicator is a leading cause of myocardial infarction in male adults [2]. Stiffening of the arterial wall causes an increase in the blood pressure by reducing the storage and buffering function of the arteries as well as by increasing the rate of pulse transmission regardless of the causes [3]. Usually, arterial stiffness worsens with aging [4]. Aging leads to thickening of the lining of blood vessels by increasing the amount of collagen in the smooth muscle layer and destroying the elastin structure [5]. These alterations result in increased arterial stiffness, leading to cardiometabolic diseases such as hypertension, diabetes, and 
dyslipidemia [6]. Body mass index (BMI), systolic blood pressure (SBP), low-density lipoprotein cholesterol (LDL-C), and vascular dysfunction are independent risk factors for cardiovascular disease [7-9]. According to a previous study, regarding the relationships among these factors, young adults with a greater number of risk factors for cardiovascular diseases showed significantly lower dilatory capacity of the brachial artery [7]. This finding suggests that vascular function is related to the risk factors for cardiovascular disease even in the younger generation, and managing the blood vessel function from a relatively younger age may be effective in preventing future cardiovascular diseases.

Pulse wave velocity (PWV) and augmentation index (AIx) are widely used as valid methods for non-invasive measurement of arterial stiffness to evaluate the function of blood vessels in human [10-13]. AIx is estimated as the ratio of waveform reflection amplitude to central pulse pressure and has a high correlation with carotid-femoral pulse wave velocity (cf-PWV), a golden standard that can directly measure central arterial stiffness [14]. The measurement of PWV is accepted as the most reliable technology through a recent consensus statement and is the most widely used technique to assess arterial stiffness $[15,16]$.

Recent studies have reported that physical fitness-related factors such as cardiorespiratory endurance and muscular strength are correlated with arterial stiffness $[17,18]$. Improving cardiorespiratory endurance with regular aerobic exercise lowers arterial stiffness and reduces the risk factors for cardiovascular diseases, consequently reducing mortality due to cardiovascular disease [19]. In addition, increasing skeletal muscle mass and muscular strength with resistance exercise has been known to prevent sarcopenia caused by aging process, and the American Heart Association recommends resistance exercise for prevention and treatment of cardiovascular diseases $[17,20]$. A study by Fahs et al. on 79 young male adults reported that upper body muscular strength was negatively correlated with aortic stiffness independent of cardiorespiratory capacity [21]. In addition, Ochi et al. study showed that the greater cross-sectional area of the thigh muscles in middle-aged male adults was associated with lower baPWV, suggesting that higher muscle strength and skeletal muscles may be correlated with arterial compliance [22]. It has been reported that an elevation in anaerobic power with anaerobic exercise has a positive effect on cardiovascular health as well as on the aerobic ability [23]. Moreover, improvement in anaerobic capacity with high-intensity interval training has a positive effect on releasing vasodilatory substances such as nitric oxide, suggesting improvement in anaerobic power has a positive effect on vascular function [24,25].

Taken together, anaerobic capacity such as skeletal muscle mass, muscle strength, and anaerobic power may be related to arterial stiffness. However, studies confirming this correlation among young adults are insufficient; especially, it is unclear whether there is a direct relationship between anaerobic power and arterial stiffness. Therefore, the present study aimed to investigate the correlation of skeletal muscle mass, muscular strength, and anaerobic power with arterial stiffness in physically-active healthy college young male adults.

\section{Materials and Methods}

\subsection{Participants}

Twenty-three healthy young male college students participated in the study. The exclusion criteria were specified as follows: (1) smokers; (2) high blood pressure $\geq$ 140/90 $\mathrm{mmHg}$; and (3) reported history of any cardiovascular, chronic, and orthopedic disease. The participants visited the laboratory between 9:00 AM and 10:00 AM. All experimental measurements were conducted with the approval of the Institutional Review Board of Incheon National University (permission\# 7007971-201904-006-01). The purpose and the procedure of the study were explained, and informed consent was obtained from all participants involved in the study prior to the experiment. The number of participations in the weekly exercise was recorded through a separate questionnaire to determine whether they participated in the exercise regularly. The weekly exercise questionnaire contained 
self-report of habitual physical activity combined into leisure-time and sports-time. Basic clinical characteristics of the participants were presented in Table 1.

Table 1. Basic clinical characteristics of participants.

\begin{tabular}{|c|c|}
\hline Variables (Unit) & Mean \pm SEM \\
\hline Age (year) & $23.9 \pm 0.5$ \\
\hline Height (cm) & $176.3 \pm 1.3$ \\
\hline Weight (kg) & $77.7 \pm 2.0$ \\
\hline Body fat $(\%)$ & $16.6 \pm 1.0$ \\
\hline Muscle Mass (kg) & $37.1 \pm 4.5$ \\
\hline Muscle Mass $\left(\mathrm{kg} / \mathrm{m}^{2}\right)$ & $11.9 \pm 0.2$ \\
\hline Hand Grip Strength $(\mathrm{kg})$ & $50.30 \pm 0.8$ \\
\hline Hand Grip Strength $\left(\mathrm{kg} / \mathrm{m}^{2}\right)$ & $16.2 \pm 0.4$ \\
\hline Peak Anaerobic Power (W) & $918.4 \pm 25.1$ \\
\hline Average Anaerobic Power (W) & $634.2 \pm 20.2$ \\
\hline Minimum Anaerobic Power (W) & $395.0 \pm 21.7$ \\
\hline $\mathrm{HR}_{\text {rest }}\left(\right.$ beats $\min ^{-1}$ ) & $60.3 \pm 2.5$ \\
\hline $\operatorname{AIx}(\%)$ & $4.0 \pm 1.4$ \\
\hline AIx@75 (\%) & $-3.1 \pm 3.0$ \\
\hline baPWV $(\mathrm{cm} / \mathrm{s})$ & $1173.5 \pm 30.4$ \\
\hline Weekly engaged exercise times (times/week) & $4.4 \pm 0.2$ \\
\hline
\end{tabular}

Values express means \pm SEM. AIx, augmentation index; AIx@75, augmentation index corrected for heart rate 75, baPWV, brachial-ankle pulse wave velocity; $\mathrm{HR}_{\text {rest }}$, heart rate at rest.

\subsection{Study Procedure}

All variables were measured in the following order: body composition, blood pressure in both arms at rest, arterial stiffness including AIx and baPWV, levels of lipid and glucose profiles in circulation, muscular strength, and anaerobic power. Participants fasted for at least $8 \mathrm{~h}$ before the measurement and were instructed to abstain from vigorous exercises or alcohol drinking for $24 \mathrm{~h}$ before visiting the laboratory. The order of measurements was arranged in such a way that the previous measure did not adversely affect the next one. Measurements for all participants were conducted at similar times and same place in a similar environment with controlled temperature $23-25^{\circ} \mathrm{C}$ and humidity $40-60 \%$.

\subsubsection{Measurements of Anthropometric Parameters and Cardiometabolic Risk Factors}

Height was measured using an extensometer (Sanwa, South Korea), and body composition was measured using an Inbody 720 (Biospace, Seoul, South Korea) machine utilizing the bioelectric impedance analysis (BIA) method. Body weight $(\mathrm{kg}), \mathrm{BMI}\left(\mathrm{kg} / \mathrm{m}^{2}\right)$, fat mass $(\mathrm{kg})$, body fat $(\%)$, and fat-free mass $(\mathrm{kg})$ were measured and obtained from BIA method. Skeletal muscle mass corrected by height $\left(\mathrm{kg} / \mathrm{m}^{2}\right)$ was used in this study $[26,27]$. Blood pressure was evaluated using Accuniq BP850 (Jawon, Seoul, South Korea). Participants measured blood pressure twice in a stable state, and the average of values was used in the analysis. For blood analysis, participants were seated in a chair and wiped their index fingers with alcohol cotton to draw whole blood. After placing the capillaries horizontally, $35 \mu \mathrm{L}$ of whole blood was collected from index finger of each participant. Total cholesterol (Total-C), LDL-C, high-density lipoprotein cholesterol (HDL-C), triglycerides (TG), and fasting glucose (FG) were measured through Cholestech LDX system (Alere, Oslo, Norway), and hemoglobin A1c (HbA1c) was measured using Afinion AS100 Analyzer (Alere, Oslo, Norway). Anthropometric parameters and cardiometabolic risk factors of all participants were presented in Table 2. 
Table 2. Anthropometric parameters and cardiometabolic risk factor of participants.

\begin{tabular}{cc}
\hline Variables (Unit) & Mean \pm SEM \\
\hline BMI $\left(\mathrm{kg} / \mathrm{m}^{2}\right)$ & $25.1 \pm 0.6$ \\
SBP $(\mathrm{mmHg})$ & $119.4 \pm 2.1$ \\
DBP $(\mathrm{mmHg})$ & $66.9 \pm 2.1$ \\
Total-C $(\mathrm{mg} / \mathrm{dL})$ & $174.6 \pm 7.5$ \\
HDL-C $(\mathrm{mg} / \mathrm{dL})$ & $54.4 \pm 2.2$ \\
LDL-C (mg/dL) & $98.9 \pm 6.7$ \\
TG (mg/dL) & $108.2 \pm 10.9$ \\
FG (mg/dL) & $91.4 \pm 2.6$ \\
HbA1c (\%) & $5.3 \pm 0.0$ \\
\hline Values express means \pm SEM. BMI body mass index; DBP, diastolic blood pressure; FG, fasting glucose; HbA1c
\end{tabular}

Values express means \pm SEM. BMI, body mass index; DBP, diastolic blood pressure; FG, fasting glucose; HbA1c hemoglobin A1c; HDL-C, high-density lipoprotein cholesterol; LDL-C, low-density lipoprotein cholesterol; SBP, systolic blood pressure; Total-C, total cholesterol; TG, triglycerides.

\subsubsection{Brachial-Ankle Pulse Wave Velocity (baPWV)}

Peripheral arterial stiffness was measured with a non-invasive method using the Omron vp-1000 plus (Omron, Tokyo, Japan). Participants waited comfortably on the experimental bed for $10 \mathrm{~min}$, placed cuffs at the same position of both upper arms and ankles, and prepared measurements by attaching electrodes to the left sternum. When the participant's resting heart rate was reached to stable condition, peripheral arterial stiffness was measured twice through an automatic waveform analyzer, and the value was obtained by calculating the movement distance and pulse wave propagation time between the limb arteries based on the height.

\subsubsection{Augmentation Index (AIx)}

AIx was assessed using SphygmoCor Xcel system (AtCor Medical, Sydney, Australia) to measure aortic stiffness in a non-invasive way. The participants lay in bed and rested for approximately $10 \mathrm{~min}$ with the cuff placed on the right upper arm. Before AIx measurement, participants' systolic and diastolic blood pressure were measured, and then AIx was measured using SphygmoCor Xcel software. The sphygmoCor device represents a pulse wave value calculated in consideration of age, heart rate, and height through a genderspecific equation [28]. AIx was obtained by dividing the augmented aortic pressure by the aortic pulse pressure. The augmented aortic pressure is made when the forward pulse wave generated from the left ventricle during the systolic period overlaps with the reflected pulse wave returned from the peripheral arterial trees. Since previous studies suggested that AIx and heart rate have a linear relationship, the value corrected to a heart rate of $75 \mathrm{bpm}$ was used in the study $[29,30]$. AIx@75 was calculated through the following mathematical formula. AIx@75 $=\{-0.48 \times(75-\mathrm{HR})\}+$ AIx [31]

\subsubsection{Muscular Strength}

Muscular strength was measured using hydraulic hand dynamometer (Saehan, Seoul, South Korea). Hand grip strength was measured in a vertical position with $15^{\circ}$ flexion at the elbow. After measuring each arm twice with an interval of $1 \mathrm{~min}$, a higher value was selected and used as a parameter of muscular strength in the study.

\subsubsection{Anaerobic Power}

Wingate test (Monark 894E model, Vansbro, Sweden) was adopted to assess the anaerobic power. The participants adjusted the position of the saddle to bend $15^{\circ}$ after the knee was completely extended from the bicycle ergometer saddle, and the participant lightly practiced pedaling at $50 \mathrm{rpm}$ for $5 \mathrm{~min}$. After a sufficient warm-up practice to relax their hip coxa and femoral muscle before the Wingate test, participants started pedaling maximum speed according to their willingness. The weight load was set to $0.075 \mathrm{~kg}$ per body weight. During the measurement, participants were encouraged orally to perform pedaling at maximum speed and power for $30 \mathrm{~s}$. In this study, the absolute and relative peak 
anaerobic power, mean anaerobic power, and minimum anaerobic power were calculated and used.

\subsection{Statistics}

Statistical analysis of all variables was performed using the SPSS version 23.0 software (SPSS Inc., Chicago, IL, USA). All measurements were presented as mean and standard error (mean \pm SEM). Pearson correlation analysis was performed after the normality test of all variables. All statistical significance levels were set to $p<0.05$.

\section{Results}

3.1. Correlation between Skeletal Muscle Mass, Muscular Strength, and Anaerobic Power

Pearson's correlation analysis was performed among skeletal muscle mass, muscular strength, and anaerobic power (peak power, average power, and minimum power). As expected, skeletal muscle mass adjusted by the height was positively correlated with muscular strength, peak power, average power, and minimum power (Table 3). In addition, muscular strength adjusted by the height was positively correlated with peak power, average power, and minimum power (Table 3 ).

Table 3. Results of Pearson's correlation analysis between skeletal muscle mass, muscular strength, and anaerobic power.

\begin{tabular}{cccccc}
\hline \multirow{2}{*}{ Variables } & \multicolumn{4}{c}{ r-Value } \\
\cline { 2 - 5 } & $\begin{array}{c}\text { Skeletal } \\
\text { Muscle Mass }\end{array}$ & $\begin{array}{c}\text { Muscular } \\
\text { Strength }\end{array}$ & $\begin{array}{c}\text { Peak } \\
\text { Power }\end{array}$ & $\begin{array}{c}\text { Average } \\
\text { Power }\end{array}$ & $\begin{array}{c}\text { Minimum } \\
\text { Power }\end{array}$ \\
\hline Skeletal muscle mass & & 0.849 & 0.625 & 0.563 & 0.468 \\
& $<0.001$ & 0.001 & 0.005 & 0.024 \\
Muscular strength & & 0.543 & 0.608 & 0.598 \\
Peak power & & 0.007 & 0.002 & 0.003 \\
Average power & & & 0.825 & 0.590 \\
Minimum power & & & $<0.001$ & 0.003 \\
& & & & 0.828 \\
\end{tabular}

Correlation coefficient is in the upper line and $p$ value in the lower one. The correlation analysis between all measurements.

\subsection{Correlation between Cardiometabolic Risk Factors and Arterial Stiffness (baPWV, AIx, AIx@75)}

Pearson's correlation analysis between risk factors for cardiometabolic diseases and arterial stiffness revealed that both AIx and AIx@75 showed a negative correlation with $\mathrm{BMI}$ and FG and no significant correlation with SBP, diastolic blood pressure (DBP), total-C, HDL-C, LDL-C, TG, and HbA1c (Table 4). In addition, a positive correlation was observed between baPWV and DBP. However, baPWV showed no correlation with other variables, including BMI, SBP, Total-C, HDL-C, LDL-C, FG, TG, and HbA1c (Table 4).

\subsection{Correlation between Muscular Variables and Arterial Stiffness (baPWV, AIx)}

Correlation between muscular variables and arterial stiffness was depicted in Figure 1. Pearson's correlation analysis revealed significant negative correlation between skeletal muscle, muscle strength, anaerobic, and AIx, respectively (Figure 1A-C). Likewise, AIx@75 (Figure 1D-F) revealed significant negative correlation with muscular variables. However, skeletal muscle mass, muscle strength, and anaerobic power showed no correlation with baPWV, respectively (Figure 1G-I). 
Table 4. Association between arterial stiffness (baPWV, AIx, and AIx@75) and cardiometabolic risk factors.

\begin{tabular}{cccccccccc}
\hline \multirow{2}{*}{ Variables } & \multicolumn{7}{c}{ r-Value } \\
\cline { 2 - 10 } & BMI & SBP & DBP & Total-C & HDL-C & LDL-C & FG & TG & HbA1c \\
\hline baPWV & 0.247 & 0.382 & 0.476 & -0.326 & 0.135 & -0.309 & 0.235 & -0.147 & -0.015 \\
& 0.256 & 0.072 & 0.022 & 0.129 & 0.539 & 0.151 & 0.281 & 0.503 & 0.946 \\
AIx & -0.636 & -0.178 & -0.084 & -0.081 & -0.151 & -0.014 & -0.513 & -0.036 & -0.068 \\
& 0.001 & 0.416 & 0.702 & 0.713 & 0.491 & 0.950 & 0.012 & 0.870 & 0.757 \\
AIx@75 & -0.557 & -0.168 & -0.021 & -0.073 & -0.119 & -0.014 & -0.483 & -0.001 & -0.022 \\
& 0.006 & 0.444 & 0.924 & 0.741 & 0.589 & 0.951 & 0.020 & 0.995 & 0.920 \\
\hline
\end{tabular}

Correlation coefficient is in the upper line and $p$ value in the lower one. AIx, augmentation index; AIx@75, AIx corrected for heart rate 75; BIA, bioelectrical impedance analysis; baPWV, brachial-ankle pulse wave velocity; DBP, diastolic pressure; FG, fasting glucose; HDL-C, high-density lipoprotein cholesterol; LDL-C, low-density lipoprotein cholesterol; TG, triglycerides; Total-C, total cholesterol; SBP, systolic blood pressure.

(A)

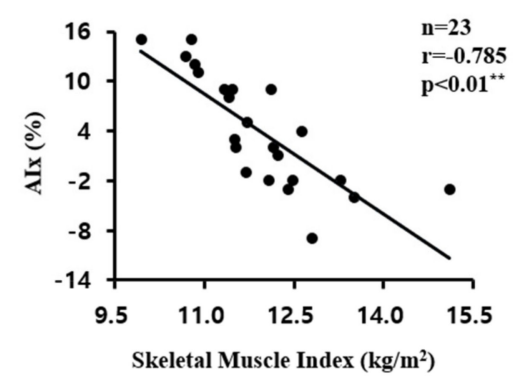

(D)

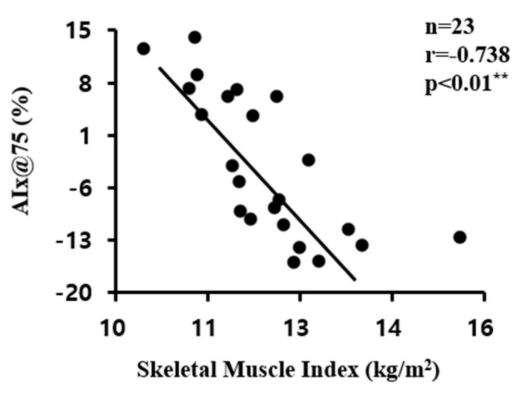

(G)

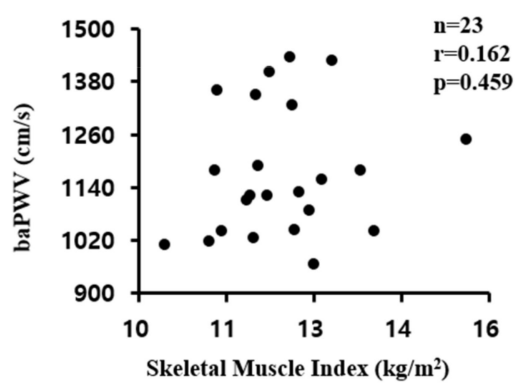

(B)

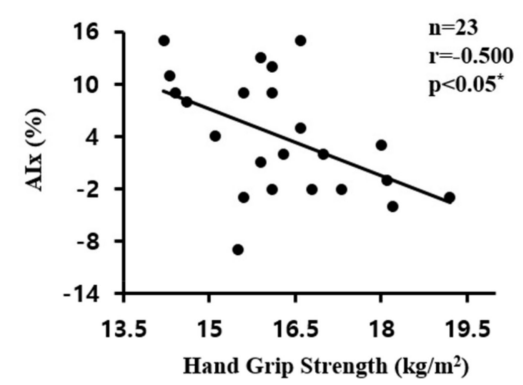

(E)

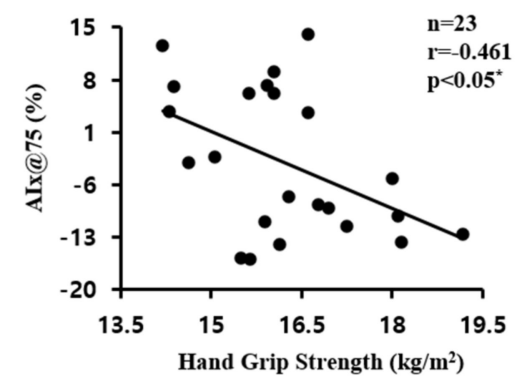

(H)

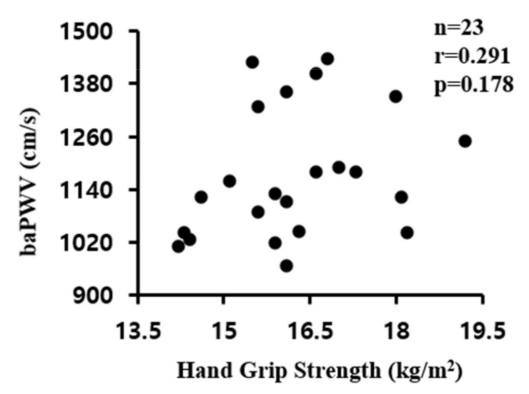

(C)

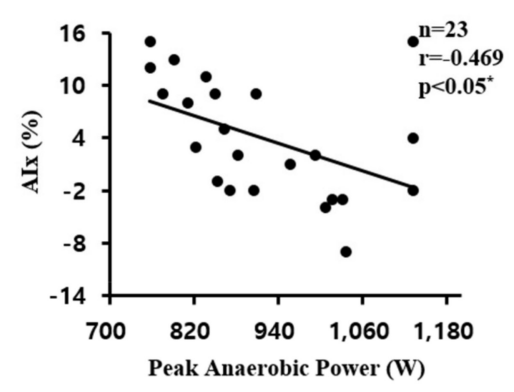

(F)

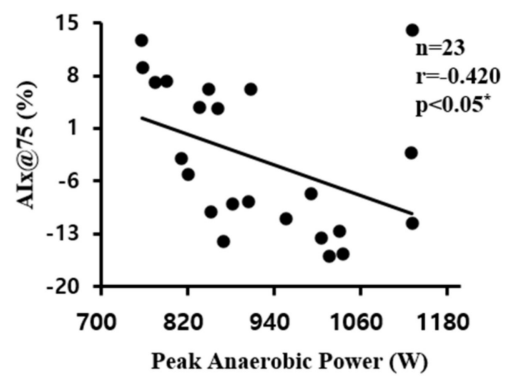

(I)

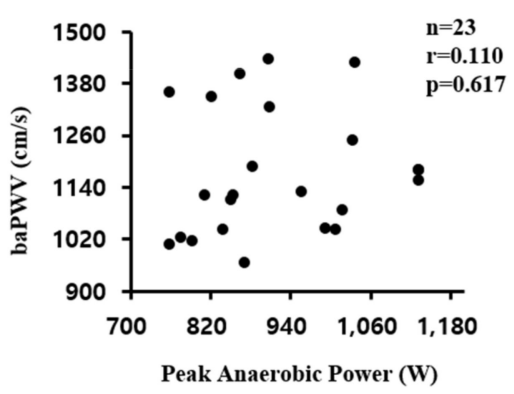

Figure 1. Associations between arterial stiffness (AIx, AIx@75, baPWV) and muscular variables (skeletal muscle mass, muscular strength, anaerobic power). Pearson's correlations between AIx and skeletal muscle index (A), hand grip strength (B), and peak anaerobic power (C). Pearson's correlations between AIx@75 and skeletal muscle index (D), hand grip strength (E), and peak anaerobic power (F). Pearson's correlations between baPWV and skeletal muscle index (G), hand grip strength (H), and peak anaerobic power $(\mathbf{I}){ }^{*} p<0.05,{ }^{* *} p<0.01$. 


\section{Discussion}

The present study aimed to examine whether muscular variables, including skeletal muscle mass, muscular strength, and anaerobic power, are related to arterial stiffness, an independent risk factor for cardiovascular disease. The major findings of the present study were that higher skeletal muscle mass, muscular strength, and anaerobic power were associated with decreased AIx, while baPWV was not associated with these muscular variables in physically-active young male adults.

This finding is consistent with the previous study, which reported a negative correlation between muscle mass and AIx in both males and females over 65 years of age [32]. In addition, according to study by Fahs et al., it represented a negative correlation between muscle strength and cf-PWV in 79 young male adults [21]; nevertheless, whether a correlation exists between AIx as a determinant of cf-PWV and muscle strength remains unknown. However, this study presented negative correlations between muscle strength and AIx, including corrected age, height, and heart rate $75 \mathrm{bpm}$. Interestingly, anaerobic power showed a negative correlation with AIx in the present study. Anaerobic power, which is an ability to express explosive energy, is an essential element for independent daily life [23]. It is well known that anaerobic power increases with elevated muscle mass and muscular strength and is improved with anaerobic training via short-term whole-body exercise [33]. Furthermore, it was reported that anaerobic power was reduced with aging and that the anaerobic energy system declined across the aging process without alteration in aerobic capacity in trained masters athletes [34]. For the most part, previous studies have examined anaerobic power in relation to sports-related performance in athletes [35,36], however, few studies have confirmed its correlation with cardiovascular risk factors [23,37]. According to previous studies, anaerobic exercise performed along with aerobic exercise has a positive effect on enhancing cardiovascular health by improving lipid components and BMI, and it improves vascular function by promoting vasodilators such as nitric oxide through high-intensity interval training $[23,24,38]$. Based on the results of this study and on those of previous studies, maintaining and increasing anaerobic power to a higher level may have a positive effect on AIx.

In the present study, skeletal muscle mass, muscular strength, and anaerobic power were not correlated with baPWV. Sugawara et al. have shown that baPWV was positively correlated with aortic PWV as well as with leg PWV [15]. Particularly, they suggested that baPWV was associated with central arterial stiffness, suggesting that baPWV may reflect central arterial stiffness as well as peripheral arterial stiffness [15,39]. However, Cortez-Cooper et al. indicated that baPWV was correlated with both central and peripheral arterial stiffness, but its correlation with peripheral arterial stiffness was stronger [40]. In addition, Laurent et al. suggested that it is clinically meaningful to evaluate central arterial stiffness rather than peripheral arterial stiffness while assessing cardiovascular diseases [16]. Taken together, central arterial stiffness may be an accurate indicator for the assessment of cardiovascular risk factors in a relatively younger age group [41]. Arterial stiffness shows a high incidence in patients with hypertension, and blood pressure is an index for predicting arterial stiffness even in young adolescents. Moreover, peripheral SBP was higher than central SBP even in adolescents, suggesting that peripheral arterial stiffness is greatly affected by blood pressure even in a relatively younger age group [42]. In case of young male adults in this study, the systolic $(119.4 \mathrm{mmHg} \pm 2.1)$ and diastolic $(66.9 \mathrm{mmHg} \pm 2.0)$ blood pressure measurements were within the normal range. Hence, baPWV may not show significant correlation in younger individuals unlike other age groups. In addition, an increase in skeletal muscle mass and muscular strength with resistance exercise may not affect peripheral arterial stiffness in young adults. For example, a study reported that lean body mass and muscular strength significantly increased after 11 weeks of high-intensity resistance exercise, but femoral-ankle PWV reflecting peripheral arterial stiffness did not ameliorate after the exercise [43]. The current study measured grip strength, an index reflecting muscular strength, and analyzed its correlation with baPWV. BaPWV accurately reflects arterial stiffness in the lower body when compared with that in 
the upper body because it reflects peripheral arterial stiffness [44]. However, grip strength is better correlated with muscle mass and muscular strength of the upper extremities and is rather limited in assessing the ability of the lower extremities [45]. This fact may explain the lack of correlation between grip strength and baPWV in this study.

Several limits of this study should be mentioned to benefit future research. First, in the present study, we conducted in a small number of healthy young male adults as a preliminary research. Therefore, the results of our study cannot be generalized to female subjects and individuals of different age ranges. Second, causality between anaerobic power and arterial stiffness was not confirmed in the present study; therefore, future studies investigating the physiological relationship between these factors are warranted.

Although the present study did not suggest the exact mechanism of how skeletal muscle mass, muscular strength, and anaerobic power mutually affect the arterial stiffness, it showed that higher skeletal muscle mass and muscular strength might have a positive effect on AIx. These findings support the fact that maintaining or improving skeletal muscle mass, muscular strength, and anaerobic power to a higher level can produce a positive effect on AIx even in the young male adults.

\section{Conclusions}

In conclusion, higher skeletal muscle mass, muscular strength, and anaerobic power are associated with decreased AIx in young male adults. However, baPWV is not associated with these muscular parameters. These findings suggest that maintaining or improving skeletal muscle mass, muscular strength, and anaerobic power to a higher level from a young age may have a positive effect on AIx.

Author Contributions: Conceptualization, D.L. and S.L.; Formal analysis, D.L., M.-H.H.; Investigation, D.L., K.B., M.-H.H., and S.L.; Methodology, D.L., K.B., and M.-H.H.; Original manuscript draft preparation, D.L. and S.L.; Review and editing, K.B., M.-H.H., and S.L. All authors have read and agreed to the published version of the manuscript.

Funding: This research received no external funding.

Institutional Review Board Statement: All experimental measurements were conducted with the approval of the Incheon National University Institutional Review Board (Permission\# 7007971-201904006-01).

Informed Consent Statement: Informed consent was obtained from all subjects involved in the study.

Data Availability Statement: Data are not publicly available due to privacy or ethical restrictions.

Conflicts of Interest: The authors declare no conflict of interest.

\section{References}

1. Dolan, E.; Thijs, L.; Li, Y.; Atkins, N.; McCormack, P.; McClory, S.; O’Brien, E.; Staessen, J.A.; Stanton, A.V. Ambulatory arterial stiffness index as a predictor of cardiovascular mortality in the dublin outcome study. Hypertension 2006, 47, 365-370. [CrossRef]

2. Weber, T.; Auer, J.; O’Rourke, M.F.; Kvas, E.; Lassnig, E.; Berent, R.; Eber, B. Arterial stiffness, wave reflections, and the risk of coronary artery disease. Circulation 2004, 109, 184-189. [CrossRef]

3. Said, M.A.; Eppinga, R.N.; Lipsic, E.; Verweij, N.; van der Harst, P. Relationship of arterial stiffness index and pulse pressure with cardiovascular disease and mortality. J. Am. Heart Assoc. 2018, 7, e007621. [CrossRef] [PubMed]

4. Lee, H.-Y.; Oh, B.-H. Aging and arterial stiffness. Circ. J. 2010, 1010120923. [CrossRef] [PubMed]

5. Sun, Z. Aging, arterial stiffness, and hypertension. Hypertension 2015, 65, 252-256. [CrossRef]

6. Lakatta, E.G. Age-associated cardiovascular changes in health: Impact on cardiovascular disease in older persons. Heart Fail. Rev. 2002, 7, 29-49. [CrossRef] [PubMed]

7. Urbina, E.M.; Kieltkya, L.; Tsai, J.; Srinivasan, S.R.; Berenson, G.S. Impact of multiple cardiovascular risk factors on brachial artery distensibility in young adults: The bogalusa heart study. Am. J. Hypertens. 2005, 18, 767-771. [CrossRef]

8. Jackson, R.; Lawes, C.M.; Bennett, D.A.; Milne, R.J.; Rodgers, A. Treatment with drugs to lower blood pressure and blood cholesterol based on an individual's absolute cardiovascular risk. Lancet 2005, 365, 434-441. [CrossRef]

9. Cook, S.; Togni, M.; Schaub, M.C.; Wenaweser, P.; Hess, O.M. High heart rate: A cardiovascular risk factor? Eur. Heart J. 2006, 27, 2387-2393. [CrossRef] 
10. Nakae, I.; Matsuo, S.; Matsumoto, T.; Mitsunami, K.; Horie, M. Augmentation index and pulse wave velocity as indicators of cardiovascular stiffness. Angiology 2008, 59, 421-426. [CrossRef]

11. Higashi, H.; Okayama, H.; Saito, M.; Morioka, H.; Aono, J.; Yoshii, T.; Hiasa, G.; Sumimoto, T.; Nishimura, K.; Inoue, K. Relationship between augmentation index and left ventricular diastolic function in healthy women and men. Am. J. Hypertens. 2013, 26, 1280-1286. [CrossRef] [PubMed]

12. Takami, T.; Saito, Y. Azelnidipine plus olmesartan versus amlodipine plus olmesartan on arterial stiffness and cardiac function in hypertensive patients: A randomized trial. Drug Des. Dev. Ther. 2013, 7, 175. [CrossRef] [PubMed]

13. Ogawa, O.; Hiraoka, K.; Watanabe, T.; Kinoshita, J.; Kawasumi, M.; Yoshii, H.; Kawamori, R. Diabetic retinopathy is associated with pulse wave velocity, not with the augmentation index of pulse waveform. Cardiovasc. Diabetol. 2008, 7, 1-5. [CrossRef] [PubMed]

14. Lee, C.W.; Sung, S.H.; Chen, C.K.; Chen, I.M.; Cheng, H.M.; Yu, W.C.; Shih, C.C.; Chen, C.H. Measures of carotid-femoral pulse wave velocity and augmentation index are not reliable in patients with abdominal aortic aneurysm. J. Hypertens. 2013, 31, 1853-1860. [CrossRef] [PubMed]

15. Sugawara, J.; Hayashi, K.; Yokoi, T.; Cortez-Cooper, M.Y.; DeVan, A.; Anton, M.; Tanaka, H. Brachial-ankle pulse wave velocity: An index of central arterial stiffness? J. Hum. Hypertens. 2005, 19, 401-406. [CrossRef]

16. Laurent, S.; Cockcroft, J.; Van Bortel, L.; Boutouyrie, P.; Giannattasio, C.; Hayoz, D.; Pannier, B.; Vlachopoulos, C.; Wilkinson, I.; Struijker-Boudier, H. Expert consensus document on arterial stiffness: Methodological issues and clinical applications. Eur. Heart J. 2006, 27, 2588-2605. [CrossRef]

17. Veijalainen, A.; Tompuri, T.; Haapala, E.; Viitasalo, A.; Lintu, N.; Väistö, J.; Laitinen, T.; Lindi, V.; Lakka, T. Associations of cardiorespiratory fitness, physical activity, and adiposity with arterial stiffness in children. Scand. J. Med. Sci. Sports 2016, 26, 943-950. [CrossRef]

18. Boreham, C.A.; Ferreira, I.; Twisk, J.W.; Gallagher, A.M.; Savage, M.J.; Murray, L.J. Cardiorespiratory fitness, physical activity, and arterial stiffness: The northern ireland young hearts project. Hypertension 2004, 44, 721-726. [CrossRef]

19. Madden, K.M.; Lockhart, C.; Cuff, D.; Potter, T.F.; Meneilly, G.S. Short-term aerobic exercise reduces arterial stiffness in older adults with type 2 diabetes, hypertension, and hypercholesterolemia. Diabetes Care 2009, 32, 1531-1535. [CrossRef]

20. Haskell, W.L.; Lee, I.M.; Pate, R.R.; Powell, K.E.; Blair, S.N.; Franklin, B.A.; Macera, C.A.; Heath, G.W.; Thompson, P.D.; Bauman, A. Physical activity and public health: Updated recommendation for adults from the american college of sports medicine and the american heart association. Med. Sci. Sports Exerc. 2007, 39, 1423-1434. [CrossRef]

21. Fahs, C.; Heffernan, K.; Ranadive, S.; Jae, S.; Fernhall, B. Muscular strength is inversely associated with aortic stiffness in young men. Med. Sci. Sports Exerc. 2010, 42, 1619-1624. [CrossRef]

22. Ochi, M.; Kohara, K.; Tabara, Y.; Kido, T.; Uetani, E.; Ochi, N.; Igase, M.; Miki, T. Arterial stiffness is associated with low thigh muscle mass in middle-aged to elderly men. Atherosclerosis 2010, 212, 327-332. [CrossRef] [PubMed]

23. Patel, H.; Alkhawam, H.; Madanieh, R.; Shah, N.; Kosmas, C.E.; Vittorio, T.J. Aerobic vs anaerobic exercise training effects on the cardiovascular system. World J. Cardiol. 2017, 9, 134. [CrossRef]

24. Thomas, G.D.; Shaul, P.W.; Yuhanna, I.S.; Froehner, S.C.; Adams, M.E. Vasomodulation by skeletal muscle-derived nitric oxide requires $\alpha$-syntrophin-mediated sarcolemmal localization of neuronal nitric oxide synthase. Circ. Res. 2003, 92, 554-560. [CrossRef] [PubMed]

25. Koral, J.; Oranchuk, D.J.; Herrera, R.; Millet, G.Y. Six sessions of sprint interval training improves running performance in trained athletes. J. Strength Cond. Res. 2018, 32, 617-623. [CrossRef] [PubMed]

26. Kim, T.N.; Park, M.S.; Lim, K.I.; Yang, S.J.; Yoo, H.J.; Kang, H.J.; Song, W.; Seo, J.A.; Kim, S.G.; Kim, N.H. Skeletal muscle mass to visceral fat area ratio is associated with metabolic syndrome and arterial stiffness: The korean sarcopenic obesity study (ksos). Diabetes Res. Clin. Pract. 2011, 93, 285-291. [CrossRef] [PubMed]

27. Baumgartner, R.N.; Koehler, K.M.; Gallagher, D.; Romero, L.; Heymsfield, S.B.; Ross, R.R.; Garry, P.J.; Lindeman, R.D. Epidemiology of sarcopenia among the elderly in New Mexico. Am. J. Epidemiol. 1998, 147, 755-763. [CrossRef]

28. Janner, J.H.; Godtfredsen, N.S.; Ladelund, S.; Vestbo, J.; Prescott, E. Aortic augmentation index: Reference values in a large unselected population by means of the sphygmocor device. Am. J. Hypertens. 2010, 23, 180-185. [CrossRef]

29. Fujime, M.; Tomimatsu, T.; Okaue, Y.; Koyama, S.; Kanagawa, T.; Taniguchi, T.; Kimura, T. Central aortic blood pressure and augmentation index during normal pregnancy. Hypertens. Res. 2012, 35, 633-638. [CrossRef]

30. Figueroa, A.; Kalfon, R.; Madzima, T.; Wong, A. Effects of whole-body vibration exercise training on aortic wave reflection and muscle strength in postmenopausal women with prehypertension and hypertension. J. Hum. Hypertens. 2014, $28,118-122$. [CrossRef] [PubMed]

31. Wilkinson, I.B.; MacCallum, H.; Flint, L.; Cockcroft, J.R.; Newby, D.E.; Webb, D.J. The influence of heart rate on augmentation index and central arterial pressure in humans. J. Physiol. 2000, 525(Pt. 1), 263-270. [CrossRef]

32. Lee, S.W.; Youm, Y.; Kim, C.O.; Lee, W.J.; Choi, W.; Chu, S.H.; Park, Y.-R.; Kim, H.C. Association between skeletal muscle mass and radial augmentation index in an elderly korean population. Arch. Gerontol. Geriatr. 2014, 59, 49-55. [CrossRef] [PubMed]

33. Marsh, G.D.; Paterson, D.H.; Govindasamy, D.; Cunningham, D.A. Anaerobic power of the arms and legs of young and older men. Exp. Physiol 1999, 84, 589-597. [CrossRef] [PubMed]

34. Gent, D.N.; Norton, K. Aging has greater impact on anaerobic versus aerobic power in trained masters athletes. J. Sports Sci. 2013, 31, 97-103. [CrossRef] 
35. Potteiger, J.A.; Smith, D.L.; Maier, M.L.; Foster, T.S. Relationship between body composition, leg strength, anaerobic power, and on-ice skating performance in division i men's hockey athletes. J. Strength Cond. Res. 2010, 24, 1755-1762. [CrossRef] [PubMed]

36. Coppin, E.; Heath, E.M.; Bressel, E.; Wagner, D.R. Wingate anaerobic test reference values for male power athletes. Int. J. Sports Physiol. Perform. 2012, 7, 232-236. [CrossRef]

37. Bera, T.; Rajapurkar, M. Body composition, cardiovascular endurance and anaerobic power of yogic practitioner. Indian J. Physiol. Pharmacol. 1993, 37, 225. [PubMed]

38. Gitt, A.K.; Wasserman, K.; Kilkowski, C.; Kleemann, T.; Kilkowski, A.; Bangert, M.; Schneider, S.; Schwarz, A.; Senges, J. Exercise anaerobic threshold and ventilatory efficiency identify heart failure patients for high risk of early death. Circulation 2002, 106, 3079-3084. [CrossRef] [PubMed]

39. Tsuchikura, S.; Shoji, T.; Kimoto, E.; Shinohara, K.; Hatsuda, S.; Koyama, H.; Emoto, M.; Nishizawa, Y. Brachial-ankle pulse wave velocity as an index of central arterial stiffness. J. Atheroscler. Thromb. 2010, 17, 658-665. [CrossRef]

40. Cortez-Cooper, M.Y.; Supak, J.A.; Tanaka, H. A new device for automatic measurements of arterial stiffness and ankle-brachial index. Am. J. Cardiol. 2003, 91, 1519-1522. [CrossRef]

41. Safar, M.; Frohlich, E.D. Atherosclerosis, Large Arteries and Cardiovascular Risk; Karger Medical and Scientific Publishers: Basel, Switzerland, 2007; Volume 44.

42. O'Rourke, M.F.; Blazek, J.V.; Morreels, C.L., Jr.; Krovetz, L.J. Pressure wave transmission along the human aorta: >changes with age and in arterial degenerative disease. Circ. Res. 1968, 23, 567-579. [CrossRef] [PubMed]

43. Cortez-Cooper, M.Y.; DeVan, A.E.; Anton, M.M.; Farrar, R.P.; Beckwith, K.A.; Todd, J.S.; Tanaka, H. Effects of high intensity resistance training on arterial stiffness and wave reflection in women. Am. J. Hypertens. 2005, 18, 930-934. [CrossRef] [PubMed]

44. Watanabe, Y.; Masaki, H.; Yunoki, Y.; Tabuchi, A.; Morita, I.; Mohri, S.; Tanemoto, K. Ankle-brachial index, toe-brachial index, and pulse volume recording in healthy young adults. Ann. Vasc. Dis. 2015, 8, 227-235. [CrossRef] [PubMed]

45. Kuh, D.; Bassey, E.J.; Butterworth, S.; Hardy, R.; Wadsworth, M.E.; Musculoskeletal Study, T. Grip strength, postural control, and functional leg power in a representative cohort of british men and women: Associations with physical activity, health status, and socioeconomic conditions. J. Gerontol. A Biol. Sci. Med. Sci. 2005, 60, 224-231. [CrossRef] 